\title{
As Peças e os Mecanismos do Crime Organizado em Sua Atividade Tráfico de Drogas
}

Adriano Oliveira

\section{INTRODUÇÃO}

\begin{abstract}
atuação do crime organizado em suas mais diversas atividades A vem sendo mostrada diariamente pelos órgãos de comunicação, em conseqüência das ações das instituições coercitivas - compreendendo-se por instituições coercitivas as Polícias, o Ministério Público, o Poder Judiciário e os Tribunais de Contas do Estado e da União. Tráfico de drogas, roubo a bancos, seqüestros, corrupção pública e rebelião em presídios são algumas das atividades dos grupos criminosos no Brasil. Contudo, apesar de o termo crime organizado ser amplamente usado por diversos autores, inclusive em obras acadêmicas, observam-se a ausência da sua definição e a explicação da sua dinâmica e seus mecanismos de atuação.
\end{abstract}

Mingardi (1996; 1998), Zaluar (1994; 2002; 2004), Rodrigues (2002; 2003), Procópio (1999) e Machado (2002) são pesquisadores que abordaram a criminalidade organizada em suas mais diversas atividades, mas não construíram uma definição objetiva do que seja crime organizado nem explicaram seus mecanismos.

Por meio de uma revisão da literatura, Mingardi aponta as características presentes em atividades criminais que devem ser reconhecidas como de organizações criminosas. Suas pesquisas abarcam as ações de

DADOS - Revista de Ciências Sociais, Rio de Janeiro, Vol. 50, n-4 4, 2007, pp. 699 a 720. 


\section{Adriano Oliveira}

grupos criminosos em diversas atividades, inclusive no jogo do bicho. Contudo, seus trabalhos não fazem referência aos mecanismos de atuação dos grupos criminosos.

Zaluar restringe sua abordagem às ações das organizações criminosas no âmbito do tráfico de drogas, mais especificamente em bairros de baixa densidade socioeconômica. Apesar de, em seus trabalhos, citar com freqüência o termo crime organizado, ela não o define. Sua obra clarifica satisfatoriamente os mecanismos de atuação dos grupos organizados no âmbito do tráfico de drogas, mas ela não torna inteligíveis as peças que integram os mecanismos provenientes das ações das organizações criminosas.

Rodrigues, Procópio e Machado desenvolvem estudos sobre o tráfico internacional de drogas. Ações de enfrentamento às drogas feitas pelos Estados Unidos no Brasil, ineficácia da política proibicionista, tráfico de drogas na Amazônia, lavagem de dinheiro e cartéis colombianos são os aspectos abordados por eles. Assim como os outros pesquisadores, esses autores usam com freqüência o termo crime organizado em seus trabalhos, mas não o definem nem explicam sua dinâmica.

Diante das lacunas existentes, este artigo tem como objetivo inicial trazer à tona, a partir da sociologia da ação (Boudon, 1995), o significado mínimo/objetivo da criminalidade organizada; em seguida, tendo como base Elster (1994), mostrar as peças que dão vida ao fenômeno da criminalidade organizada e seus mecanismos. Segundo Elster,

\footnotetext{
“Um mecanismo causal tem um número de elo. Cada elo terá de ser descrito por uma lei geral, e nesse sentido por uma 'caixa preta' sobre cujas engrenagens e polias permanecemos ignorantes. No entanto, para propósitos práticos - o lugar da ênfase é importante. Ao concentrarmos em mecanismos, captamos o aspecto dinâmico da explicação científica: o impulso de produzir explicações cada vez mais refinadas" (idem:21).
}

Após a abordagem teórica, desenvolve-se um estudo empírico com o objetivo de comprovar os mecanismos do crime organizado em sua atividade tráfico de drogas. "Nas ciências sociais, um enunciado é 'verdadeiro' quando passa o teste do controle empírico, e é considerado falso quando falha neste teste" (Sartori, 1997:63, ênfases no original). Nesse sentido, com base em documentos sigilosos do Ministério Público Fe- 
deral e da Polícia Federal, além de entrevistas, será analisada a atuação de um grupo criminoso no tráfico internacional de drogas.

Este artigo pretende evidenciar o conceito mínimo da criminalidade organizada para que sirva de parâmetro para novas pesquisas na área. A evidência das peças que integram os mecanismos do crime organizado e suas interações também tem o mesmo objetivo. Por fim, o artigo fornece subsídios para incentivar a produção acadêmica em torno das ações de grupos criminosos no Brasil, especialmente no âmbito do tráfico de drogas, uma vez que essa atividade ilícita ameaça a existência legal do poder coercitivo estatal.

\section{O QUE É CRIME ORGANIZADO?}

Oliveira (2006), por meio de uma ampla revisão da literatura, traz à tona os diversos traços da criminalidade organizada. Dentre esses, destacam-se os apresentados por Mingardi (1996) e pelas United Nations Office on Drugs and Crime (2002). Para Mingardi, os grupos criminosos têm as seguintes características: prática de atividades ilícitas; atividade clandestina; hierarquia organizacional; previsão de lucros; divisão do trabalho; uso da violência; simbiose com o Estado; mercadorias ilícitas; planejamento empresarial; uso da intimidação; venda de serviços ilícitos; relação clientelista; presença da lei do silêncio; monopólio da violência e controle territorial.

Algumas características expostas pelas United Nations confundem-se com as de Mingardi. Contudo, as United Nations construíram as características dos grupos criminosos por meio de um estudo empírico em 16 países e analisaram a ação de 40 organizações criminosas. Por conseqüência, frisam que a criminalidade organizada tem estrutura/hierarquia; é composta por, no mínimo, dois membros, chegando certas organizações a ter mais de 100 membros; atua de modo local ou internacionalmente; seus integrantes fazem uso da corrupção perante o poder estatal e suas ações ilícitas penetram na economia legal. As características apontadas não devem ser desconsideradas. Contudo, são amplas e, conseqüentemente, não permitem a definição objetiva do termo crime organizado, que se faz necessária, porque, desta forma, a compreensão do fenômeno será facilitada. Além disso, não é possível analisar um objeto ou fenômeno social sem definir seu significado mínimo (Sartori, 1997). 
Contrariando Zaffaroni (1996), que compreende ser impossível a categorização do crime organizado, e por meio da sociologia da ação, a qual reconhece que todo fenômeno social é sempre o resultado de ações individuais (Boudon, 1995:28), define-se o crime organizado. Este deve ser compreendido na perspectiva da sociologia da ação e levando-se em consideração que os indivíduos são racionais. Nesse sentido, parte-se do seguinte princípio: a atividade humana é orientada por seus objetivos, e os indivíduos tentam promover ao máximo sua realização, buscando os meios mais eficientes para consegui-los (Tsebelis, 1998:21).

Os indivíduos tomam suas decisões racionais considerando as características do contexto social em que estão presentes e as ações dos outros participantes. Para Tsebelis, "[...] o enfoque da escolha racional assume que o comportamento do indivíduo é uma resposta ótima às condições de seu meio e ao comportamento de outros atores" (idem:56). No contexto social, existem incentivos inteligíveis que podem influenciar os atores na sua tomada de decisão. O que orienta a decisão dos sujeitos racionais são os resultados, e, para a conquista de seus objetivos, devem ser escolhidos os meios mais eficientes (Elster, 1994). Os sujeitos, ao tomarem suas decisões em um determinado contexto, devem estar informados sobre as regras existentes (Tsebelis, 1998), que podem ser criadas intencionalmente, ou seja: eles criam regras para maximizar os benefícios. As regras criadas são as que possivelmente regularão a interação dos participantes e orientarão suas ações. O indivíduo pode agir contrário às regras e, com isso, ser irracional; ou ele pode descobrir que agir de modo contrário às regras é a atitude mais racional. Portanto, é de vital importância que um indivíduo racional esteja bem informado no âmbito do seu contexto de ação para tomar sua decisão racional.

Ao possibilitar a compreensão da escolha dos indivíduos, a escolha racional permite que o observador adquira o entendimento dos incentivos que influenciam as tomadas de decisão dos atores. A descoberta desses incentivos é de extrema importância para o observador, porque, com o entendimento desses incentivos, ficarão evidentes as preferências dos atores - inclusive a ordem das preferências (Elster, 1986; 1994). Um exemplo de escolha por meio da ordem de preferências é o motivo que leva um indivíduo a deixar de agir sozinho para o fazer em grupo. Em conformidade com a escolha racional, verifica-se que não existe nenhum sentido na formação de uma organização quando uma ação "in- 
dividual independente pode servir aos interesses do indivíduo tão bem, ou melhor, do que uma organização" (Olson, 1999:19).

Assim, os indivíduos formam uma organização econômica ou criminal por saberem que, mediante ela, podem ampliar seus ganhos. É importante frisar que as instituições (como sinônimo de organizações) são mecanismos para alcançar "propósitos, não apenas para alcançar acordos" (Putnam, 2002:24). Nesse caso, as organizações criminosas são reconhecidas como instituições criadas intencionalmente por um ou mais de um indivíduo. Pode-se afirmar, portanto, que o crime organizado é uma instituição - formada por mais de um indivíduo - criada para aumentar e distribuir benefícios entre os envolvidos. Regras são criadas pelos membros da organização com o objetivo de facilitar a relação entre eles; como também para permitir a relação com outros indivíduos que não pertencem à organização, por exemplo, agentes estatais.

É importante destacar que Mingardi (1996) e as United Nations (2002) fazem referência à relação entre Estado e grupos criminosos. No caso, a busca do apoio do poder estatal por parte das organizações criminosas é apontada como uma das características das ações de grupos criminosos.

Desse modo, e concordando com Oliveira (2006), deve-se aferir o poder de um grupo criminoso com base no apoio que ele consegue no Estado. Nesse sentido, quanto mais um grupo criminoso conquista atores no Estado - que facilitam suas atividades criminosas e, por conseqüência, lhe dão apoio -, mais poder ele conquista (idem:105).

\section{OS MECANISMOS DA CRIMINALIDADE ORGANIZADA}

Quando uma organização é formada, seu objetivo deve ser verificado. A compreensão do propósito permitirá que os mecanismos de funcionamento e os interesses da organização sejam visualizados (Olson, 1999:17). Assim, quando uma organização criminosa decide buscar agentes estatais para cooperar com ela, evidencia-se que o Estado é um meio que poderá proporcionar o aumento dos seus benefícios, ou garantir o funcionamento estável das suas atividades.

Regras que viabilizam instituições podem ser criadas intencionalmente pelos atores para possibilitar acordos. Por exemplo: um grupo de indivíduos (grupo A) deseja maximizar seus benefícios, mas só pode conseguir seu objetivo se cooperar com o grupo B, que também deseja fazer o mesmo. Os grupos desejam a cooperação, mas faltam regras 
que as possibilitem. Nesse sentido, as regras serão criadas pelos grupos para regulamentar e orientar suas ações, possibilitando, assim, a maximização dos benefícios de todos.

O reconhecimento das ações dos sujeitos como racionais facilita a explicação por mecanismos. Nesse caso, em cada peça, há um sujeito racional que toma decisões intencionais com o objetivo de conquistar benefícios e maximizá-los. Nesse sentido, suas ações, quando reconhecidas como racionais, tornam inteligíveis seus objetivos e, por conseguinte, permitem a compreensão das possíveis interações das peças presentes nos mecanismos da criminalidade organizada.

Por exemplo: por que $X$, membro de uma organização criminosa, decidiu procurar o agente estatal $Y$ ? Ou por que $Y$ decidiu aceitar colaborar com X? Reconhecer a ação intencional e racional dos sujeitos possibilita o encontro das respostas a estas indagações. Ressalte-se que $X$ faz parte de uma peça e $Y$, de outra. "[...] a explicação por mecanismos opera quando e porque podemos identificar um padrão causal que se pode conhecer entre situações e que fornece uma resposta inteligível para a pergunta: por que os indivíduos fizeram aquilo?" (Ratton Júnior, 2003:178, ênfases no original). A interação das peças representa eventos. No caso aqui relatado, dois eventos existem, ou seja: $X$ procura $Y$ para cooperar por algum motivo (primeiro evento); $Y$ decide cooperar com $X$ por outro motivo (segundo evento).

Para Elster, a relação causal que possibilita a explicação por mecanismos é pensada obedecendo a três princípios: determinismo, localidade e assimetria temporal. No caso do primeiro, deve-se entendê-lo conforme o seguinte postulado: todo evento tem uma causa. O determinismo pode "ser entendido como o postulado de que qualquer evento tem uma causa: um determinado conjunto de antecedentes causais que são conjuntamente suficientes e individualmente necessários para a sua ocorrência" (Ratton Júnior, 2003:148).

A explicação por mecanismos diferencia-se do mero relato descritivo e tem quatro características fundamentais: 1) as ações dos indivíduos e suas conseqüências são, prioritariamente, levadas em consideração; 2) os fenômenos sociais resultam da ação e da interação dos indivíduos; 3) as condições que possibilitam a existência de um ou mais mecanismos devem ser verificadas; 4) a caixa-preta, que é formada por peças, deve ser aberta, isto é: os motivos e os efeitos presentes em uma relação 
entre peças precisam ser compreendidos, além dos processos inerentes a eles (idem:170-172).

A explicação por mecanismos, conforme exemplifica Ratton Júnior, baseia-se em Elster, que a define da seguinte maneira:

"[...] explicar é fornecer mecanismos, abrir a caixa-preta e mostrar as peças e engrenagens, porcas e parafusos da maquinaria interna da vida social. O termo mecanismo relaciona-se a cadeias intencionais de um objetivo para uma ação, como também cadeias causais de um evento para o seu efeito. O papel dos mecanismos é duplo: eles nos tornam capazes de ir do maior para o menor, das sociedades para os indivíduos [...]. Um mecanismo fornece uma cadeia contínua e contígua de links intencionais e causais: ele abre uma caixa-preta, que é uma falha, algo obscuro, na cadeia explicativa" (idem:176-177, ênfase no original).

Oliveira (2006), utilizando a explicação por mecanismos, analisa empiricamente a ação de diversos grupos criminosos. Em conseqüência, ele aponta as principais peças que integram os mecanismos do fenômeno da criminalidade organizada: poder institucional cooperativo, poder econômico e a própria organização criminosa. Essas peças podem estar ou não em processo de interação. Isso significa que, em uma dada dinâmi$\mathrm{ca} /$ mecanismos, a organização pode estar atuando solitariamente, sem interagir com as outras peças. Contudo, em outro instante, o grupo criminoso pode estar interagindo com as outras peças, ou apenas com uma.

Com o auxílio de dados empíricos e de uma ampla revisão da literatura que aborda o tráfico de drogas, Oliveira (idem) mostra as possíveis peças que integram os mecanismos do tráfico de drogas, independentemente de ele ser desenvolvido por grupos criminosos ou por traficantes que atuam solitariamente. Nesse sentido, duas novas peças surgem em relação aos mecanismos do crime organizado: tráfico formiguinha e mercado consumidor.

A peça mercado consumidor reflete a clientela que está em processo de interação com o traficante ou com um grupo criminoso. Nesse caso, ambos oferecem drogas aos consumidores. Portanto, existe um processo de interação do grupo criminoso ( $p e c ̧ a B)$ com os consumidores de drogas (peça A).

A peça tráfico formiguinha representa os vapores, ou seja, os que intermedeiam o comércio de drogas entre a organização criminosa e o con- 
sumidor. O traficante formiguinha leva consigo pequena quantidade de drogas e tem sempre de ir buscá-las para oferecer aos consumidores. Desse modo, observa-se a seguinte interação das peças: o traficante formiguinha/vapor (peça $E$ ) interage com as peças $B$ e $A$. As outras peças, poder econômico (peça $D$ ) e poder institucional cooperativo (peça C), podem estar, em algum instante, também em processo de interação. Nesse caso, verifica-se a presença de uma dinâmica totalizante e complexa, porque todas as peças mostradas estão em processo de interação.

A seguir, com o objetivo de comprovar empiricamente a presença dessas peças na atividade de uma organização criminosa, será desenvolvida uma análise em torno de um grupo criminoso que atuou no âmbito do tráfico internacional. Desse modo, espera-se mostrar que o conceito de crime organizado e a explicação por mecanismos e suas peças, mostrados neste artigo, têm validade empírica.

\section{ORGANIZAÇÃO DIAMANTE}

Esta seção, elaborada com base em entrevistas, notícias da imprensa e documentos do Ministério Público Federal e da Polícia Federal, analisa a dinâmica/mecanismos de um grupo criminoso de grande envergadura, aqui denominado organização Diamante. Mostra como seus integrantes conseguiram interferir em diversas instituições do Estado em conseqüência de consideráveis recursos financeiros geridos por essa organização e, por fim, os meios utilizados para a lavagem de dinheiro.

No final desta, além da comprovação empírica dos mecanismos do tráfico de drogas, ficará nítido como alguns grupos criminosos interferem nas ações das instituições coercitivas e que, no Brasil, o tráfico de drogas ameaça a própria existência do Estado.

\section{O Grande Grupo, as Forças Armadas Revolucionárias da Colômbia - FARC e Fernandinho Beira-Mar}

Em janeiro de 2003, o procurador da República Gustavo Pessanha

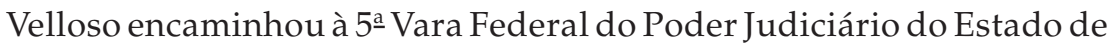
Goiás uma denúncia contra 37 pessoas por associação para a prática de tráfico internacional de entorpecentes. De acordo com a denúncia no 48/2003 oferecida pelo Ministério Público Federal, essas pessoas fa- 
zem parte de uma organização criminosa muito bem estruturada, qualificada como a "maior de que no Brasil se teve notícia".

A atividade principal desse grupo criminoso é o tráfico internacional de cocaína. Daí advêm lavagem de dinheiro, sonegação fiscal, cooperação entre o grupo e agentes estatais, assim como o uso de paraísos fiscais. Não fica claro na denúncia do Ministério Público Federal, que consta do Inquérito Policial no 2003.35.00.013320-9 da Polícia Federal, nem em entrevistas com pessoas que enfrentaram ou fizeram parte da organização, o papel e a função laboriosa de cada participante do grupo. Doleiros, "laranjas", pilotos de avião, seguranças, transportadores, fornecedores, advogados, funcionários públicos e gerentes de banco foram participantes - principais ou secundários - da dinâmica do tráfico de drogas exercida pela organização Diamante.

Com base em diversas fontes de informação, fica evidente como todas as peças mostradas integravam os mecanismos da organização. Compreendendo as peças por parte, percebe-se que esse grupo criminoso tinha inicialmente dois líderes, outro integrou-se à organização, mas rompeu posteriormente com um dos líderes originais. Na verdade, havia três grupos criminosos que, em determinado momento, se uniram, possibilitando a formação de uma única organização criminosa, a Diamante. A denúncia do Ministério Público Federal inclui todos os participantes em uma única organização criminosa.

Os grupos criminais atuam no início separadamente, com o caminhar da atividade criminosa, eles se juntam. Muitos desses grupos contam com a participação da esposa, sogros ou irmãos do líder da organização - como é o caso do grupo de Leonardo Dias Mendonça. Em 1999, na apreensão de 327 quilos de cocaína em Mato Grosso, constatou-se que uma pessoa, aqui denominada "Carlos", era traficante. Em agosto de 1999, a Polícia Federal obteve informações que revelaram a cooperação profissional entre Leonardo Mendonça e esse suposto traficante.

Alguns traficantes brasileiros, como Leonardo Mendonça, buscam cooperação com negociadores de drogas em outros países. Tudo indica que não há monopólio na atividade do tráfico internacional de drogas; traficantes constroem laços com o objetivo de fortalecer seus negócios. Leonardo tinha ligações com traficantes colombianos, e Carlos atuava em parceria com criminosos residentes no Suriname. Com essa relação estabelecida, formou-se outra organização. Unidos, eles obtêm pontos de apoio e de negócios tanto na Colômbia como no Suriname. 
Contudo, existe concorrência interna. Leonardo Mendonça estava importando grandes quantidades de cocaína da Colômbia. O sucesso dessa importação estava propiciando alto ganho financeiro, visto que Leonardo havia conquistado a confiança e o respeito do fornecedor. Diante disso, outro traficante do Brasil estava impossibilitado de apanhar cocaína com o mesmo fornecedor. Receoso, o traficante solicitou permissão a Carlos, que respondeu: "O dono do negócio é o baixinho", referindo-se a Leonardo.

A interação dos grupos criminosos ocorre com o objetivo de somar capital. Tanto Leonardo como Carlos apanhavam grande quantidade de cocaína, quase sempre acima dos 100 quilos - chegando a um carregamento de 400 quilos. Muitas vezes, as negociações com outros comerciários de droga, mais especificamente os fornecedores de cocaína, eram estabelecidas do seguinte modo: entrega-se a droga e, de imediato, é feito o pagamento. Por conta disso, há necessidade de união entre as organizações, ou seja, os traficantes precisam de capital de giro.

Os grupos criminosos ou a organização criminosa às vezes não dispõem de recursos financeiros para o imediato pagamento da droga. Nesse caso, a união permite que o líder de um grupo entregue seu avião como pagamento, e o de outro utilize a aeronave para apanhar a droga. Uma aeronave usada habitualmente para o transporte de droga na rota Colômbia-Brasil pode render 40 quilos de cocaína.

Carlos foi preso no Suriname quando embarcava bazucas e fuzis em uma aeronave. As armas tinham como destino as FARC. Carlos não estava levando armas para a guerrilha porque era comunista, mas sim para trocar armas por cocaína. Essa ação, que se repetiria algumas vezes enquanto Leonardo Mendonça estava em atividade, mostra que as FARC, de fato, trocam armamentos por drogas, não importando a nacionalidade do traficante. Depois da prisão de Carlos, Leonardo não o abandonou; fazia chegar à esposa de Carlos valores em torno de R $\$ 30$ mil. Mesmo preso no Suriname, Carlos continuava atuando no tráfico de armas e de cocaína. Em 31 de outubro de 2001, por volta das 18 horas, conseguiu fugir da prisão, voltando a atuar com Leonardo.

Em 4 de dezembro de 2000, a associação entre Leonardo Mendonça e Carlos foi desfeita. Os negócios de Leonardo cresceram muito, independentemente da parceria com Carlos. Leonardo passou a fornecer droga a compradores da Guiana. Estes, considerados possuidores de um capital em torno de US\$4.500.000,00, remetem a cocaína para os 
Estados Unidos. Por intermédio de uma firma de exportação paulista, Leonardo Mendonça estava enviando cocaína para a Europa, chegando a movimentar cerca de US\$1.300.000,00 em uma única negociação. Por várias vezes, a denúncia do Ministério Público Federal mostrou o uso de empresas de exportação para o envio de cocaína a outros países, a exemplo de firmas que enviam a matéria-prima papel ao exterior em contêineres onde a droga é escondida e transportada para o antigo continente.

Leonardo, por meio de outros interlocutores, continuou cooperando com as FARC diretamente, sem a presença do parceiro Carlos. Os interlocutores de Leonardo possivelmente chegaram a se encontrar com Tomás Medina Caracas, o Negro Acácio, qualificado por autoridades colombianas e americanas como o líder das FARC que atua no tráfico de drogas e de armas. Conforme relatórios da Polícia Federal e informação do Ministério Público Federal, era rotina o escambo de cocaína por armas.

De acordo com o Ministério Público Federal e a Polícia Federal, Leonardo Mendonça mantinha parceria com Fernandinho Beira-Mar, a quem Leonardo chamava Águia Grande. Em alguns momentos, Leonardo procurou resolver as questões judiciais de Beira-Mar, mas não obteve sucesso. A associação comercial entre os dois traficantes tinha como objetivo o aumento de capital e, conseqüentemente, a compra de mais cocaína. Essa união não se restringia apenas a eles; Leonardo mantinha parceria comercial com traficantes paulistas, e Beira-Mar com traficantes cariocas.

Fernandinho Beira-Mar chegou a capitalizar Leonardo para a compra de droga mediante empréstimo. Ao acumular um total de US\$ 1.300.000,00 de dívida com Beira-Mar, Leonardo passou a ser cobrado. Como demorou a dar uma resposta de como pagaria a dívida, Beira-Mar o ameaçou. Leonardo ofereceu fazendas e postos de gasolina ao traficante carioca, mas ele não aceitou. Com temor de ser executado, ou de ter algum ente de sua família morto, Leonardo articulou a execução de Beira-Mar, que lhe custaria US\$3.000.000,00. Leonardo achou caro, e o interlocutor argumentou que só a dívida cobrada era de US\$1.800.000,00. 


\section{Proteção Institucional e Lavagem de Dinheiro}

A busca de cooperação com agentes estatais foi um meio muito usado por Leonardo Mendonça para manter seus negócios em expansão. Polícia Federal, Poder Judiciário e Câmara dos Deputados são instituições usadas pelo traficante como um recurso eficaz para o sucesso de suas atividades. Após uma negociação com outro traficante preso pela Polícia Federal, Leonardo presenteou um agente da Polícia Federal de Marabá (PA) com um automóvel. Por intermédio de seu advogado, Leonardo obteve informações sobre um relatório de inteligência do Setor de Investigação da Polícia Federal, com 50 páginas, que contém os telefones grampeados dos integrantes da organização Diamante. Em conversa com um agente federal, Leonardo soube que um superintendente da Polícia Federal, que tem negócios com bocas-de-fumo, sumiu com 10 quilos de cocaína.

Com o objetivo de pagar parte da dívida que tinha com Fernandinho Beira-Mar, Leonardo Mendonça tentou, várias vezes, recuperar uma considerável quantia de dólares apreendida pela Polícia Federal do Rio de Janeiro. Após a intermediação de quatro delegados, um deles aposentado, Leonardo recebeu a promessa de liberação, porque os dólares não estavam mais sob o controle da Justiça, mas da Polícia Federal. Desse modo, para a liberação, seria suficiente uma medida administrativa. Em uma conversa telefônica, o interlocutor de Leonardo Mendonça disse que a liberação dos dólares pela Polícia Federal estava resolvida, mas frisou que estava à espera da decisão da Justiça; por conta disso, estava nas mãos de um advogado, filho de um ministro do Supremo Tribunal Federal - STF.

Uma juíza do Poder Judiciário de Mato Grosso foi alvo constante do advogado de Leonardo Mendonça, que, em uma ligação telefônica, frisou: "O mato foi derrubado [...] e jogada a semente." O profissional de Direito estava comunicando a Leonardo que as dificuldades com a juíza foram superadas. Em alguns diálogos com Mendonça, o traficante se referia a ela como a "dona de casa".

Certa vez, o advogado foi informado, com antecedência, sobre um mandado de prisão emitido pela Justiça Federal do Maranhão em favor de Leonardo Mendonça. Em um diálogo com dois membros de sua organização, Leonardo fez menção a um depósito de R 94 mil, que deveria ser usado para a concessão de medidas liminares pelos Tribunais 
Superiores. Em outra ligação, esse valor aumentou para R \$ 240 mil: R \$ 120 mil pagos no dia solicitado, e o restante na semana seguinte.

O então deputado federal Pinheiro Landim (PMDB-CE), denominado "cabeça branca" por alguns integrantes da organização Diamante, tinha a função de pressionar e intermediar as negociações com os membros do Poder Judiciário. Por intermédio do deputado, foram conquistadas decisões favoráveis por parte da Justiça e concessão de liminares. Pinheiro Landim teria cobrado $\mathrm{R} \$ 100$ mil para auxiliar na concessão de habeas corpus (O Estado de S. Paulo, 2002).

Esse parlamentar não era o único a ser usado pela organização Diamante para pressionar os membros do Poder Judiciário. O filho do desembargador federal Eustáquio da Silveira, conhecido como Igor, foi tido, em 2002, como suspeito de ser o líder de uma rede de influências que atuava no Tribunal Regional Federal - TRF da 1르 Região e no Superior Tribunal de Justiça - STJ (idem).

A grande movimentação financeira de Leonardo Mendonça, que rendia cerca de US $\$ 1.300 .000,00$ em um carregamento de cocaína, fornecia-lhe recursos para conquistar a colaboração dos agentes estatais. Tal colaboração possibilitava a proteção institucional, isto é: agentes do Estado, em vez de combater a organização por meio dos seus recursos constitucionais, usam da sua função para proteger e facilitar atividades ilícitas. Nesse sentido, as instituições estatais, por meio de seus integrantes, concedem proteção a sujeitos que praticam atos proibidos por lei. Como era arriscado esconder alta soma de recursos em casa, a lavagem de dinheiro era freqüentemente usada pelo traficante. Compra de postos de gasolina no Maranhão, aquisição de imóveis, fazendas e touros, depósitos em contas de "laranjas" e as casas de câmbio eram meios usados por Leonardo para encobrir a origem ilícita de seus recursos.

\section{Versão de Leonardo Mendonça}

Leonardo Mendonça nega que seja traficante de drogas: "[...] de droga não tenho conhecimento nenhum. [...] de dólares, muito menos". Para ele, a polícia o criou, e a mídia reforçou essa criação: "[...] quando a mídia entra num processo, a Justiça sai pela outra porta". Leonardo disse que responde a três processos, todos iniciados pelo delegado da Polícia Federal Ruy Anderson. O suposto traficante se diz vítima de persegui- 
ção do delegado. Questionado sobre o motivo dessa perseguição, ele disse que sabe, mas não pode dizer por não ter provas.

Leonardo afirmou que o delegado chegou a torturar um piloto de avião, forçando-o a assinar um depoimento contra ele. Segundo Leonardo, a ação do delegado não parou ali. Em 2000, na Comissão Parlamentar de Inquérito - CPI do Narcotráfico Federal, o delegado e os deputados Celso Russomano, Magno Malta e Alcione Barbalho, por conta de uma audiência pública no Pará, propuseram a alguns traficantes de drogas da região que dissessem em depoimento que certa quantidade de droga apreendida no Maranhão era de Leonardo Mendonça.

Quando questionado sobre as informações a respeito de seu suposto envolvimento com as FARC, Leonardo respondeu: "Nunca estive na Colômbia". De acordo com ele, sua riqueza foi conquistada com garimpos localizados no Suriname e na Venezuela. Sua estada no exterior não tinha o objetivo de negociar com as FARC, mas lucrar com seus garimpos. Leonardo acrescentou que, entre 1990 e 1993, explorava uma pista de garimpo onde desciam 100 aviões por dia para serem abastecidos com ouro.

"Não conheço Fernandinho Beira-Mar e nunca encomendei a morte dele. [...] Também nunca devi dinheiro a ele". Esta foi a resposta de Leonardo ao ser indagado sobre as informações de que ele atuava em parceria com o traficante carioca. A mesma resposta foi dada quanto à sua possível relação com o ministro Vicente Leal, do STJ: "Conheço só de ouvir falar". Contudo, Leonardo relatou que, certa vez, teve um diálogo com um delegado da Polícia Federal de Belém:

“Então, esse delegado de Belém disse: 'Olhe, já saiu sua sentença de Mato Grosso. Você pode dizer tudo o que quiser, porque agora vou resguardar sua família'. [...]. Eu disse que não tinha nada para dizer. Ele perguntou: 'Você não quer falar do pessoal de Brasília?' Eu perguntei: falar o quê? E ele: 'Do pessoal do tribunal'. Que tribunal, que pessoal? Ele respondeu: 'Você fala do Eustáquio, do Tourinho e do Vicente Leal. Acuse, que eu lhe dou proteção'."

Ao perguntar qual o interesse do delegado ao fazer essa proposta, Leonardo respondeu que alguns delegados da Polícia Federal têm interesse em incriminar o "pessoal do tribunal". Leonardo frisou que nunca tentou corromper ninguém, no entanto, ele não sabe nem tem interesse 
em saber quais os métodos utilizados por seus advogados para conquistar suas solturas por meio de habeas corpus.

Diante dos últimos dizeres de Leonardo, convém informar:

a) Em 10 de outubro de 2000, por decisão da 6 a turma do STJ, Leonardo Mendonça conquistou seu primeiro habeas corpus; em 16 de outubro de 2000, foi preso novamente com 327 quilos de cocaína; em 6 de março de 2001, a 4a turma do TRF autorizou sua liberdade; em 4 de outubro de 2001, novamente Leonardo foi preso no Maranhão com 141 quilos de cocaína; mais uma vez, teve habeas corpus concedido pela turma de férias do TRF em 24 de janeiro de 2002.

b) O desembargador federal Eustáquio da Silveira, em 20 de fevereiro de 2003, foi afastado do cargo por suspeita de envolvimento com Leonardo Mendonça; é importante salientar que o desembargador esteve em Goiânia, em 13 de março de 2003, acompanhado de seu assessor, o delegado aposentado da Polícia Federal João Batista Campelo, para denunciar ao corregedor da Polícia Federal de Goiás Vantuil Cordeiro manobras da Polícia Federal e do juiz federal José Godinho Filho para incriminá-lo (Furtado, 2003).

c) Em 12 de abril de 2003, o Órgão Especial do TRF da 1a Região, em decisão inédita, determinou a aposentadoria compulsória e remunerada do desembargador Eustáquio da Silveira; o julgamento durou cerca de 20 horas, e os 18 integrantes do Órgão Especial concluíram que o desembargador teve desvio de conduta por ter orientado advogados a encaminhar pedidos de habeas corpus em favor de traficantes de drogas (Terra, 2003).

d) Em abril de 2003, em decisão inédita, por 30 votos a zero, os ministros do STJ, pela primeira vez na história, decidiram afastar o ministro Vicente Leal de suas funções em razão de seu possível envolvimento com um esquema de venda de sentenças para traficantes; porém, às vésperas da conclusão do processo administrativo, que durou vários meses, o ministro Vicente Leal solicitou ao presidente do STJ, Edson Vidigal, seu pedido de aposentadoria; a célere tramitação do expediente permitiu que o ministro Vicente Leal conseguisse sua aposentadoria, e o processo administrativo perdeu seu objetivo; enfim, Vicente Leal não foi punido.

Leonardo Mendonça revelou que, por intermédio de seu advogado, um escritório de advocacia dos Estados Unidos lhe fez uma proposta de 
concessão da cidadania americana em troca de parte de sua riqueza. Fato inusitado e estranho. Continuando, Leonardo disse em entrevista:

“[...] eles vieram me propor, através de meu advogado, que queriam me levar para os Estados Unidos porque eu sei muito, conheço muito de tráfico [...]. Eles disseram que eu tinha US $\$ 500.000 .000,00$ fora do país [...] e eles legalizariam meu dinheiro. Isso significaria US\$ 250.000.000,00 para mim e US\$ 250.000.000,00 para os Estados Unidos, e me dariam a cidadania e tudo o mais. Essas são as propostas que chegam. [...]. Eles me mandaram uma carta de um escritório de advocacia. [...]. Eu disse a eles que não, [...], pois não existe esse dinheiro. Jogaram uma isca para ver se eu engolia. [...]. Não foi a DEA".

\section{OS MECANISMOS DA ORGANIZAÇÃO DIAMANTE: COMPROVAÇÃO EMPÍRICA}

As informações quanto às ações do grupo criminoso Diamante evidenciam a presença de todas as peças já apresentadas que integram os mecanismos do tráfico de drogas. Desse modo, existe uma dinâmica totalizante e complexa, visto que todas as peças estão envolvidas.

Com o intuito de confirmar essa afirmação, conforme a Figura 1, identificam-se os participantes em cada peça. As setas representam a interação das peças, o que possibilita os mecanismos. Nesse sentido, a presença de uma peça possibilita a existência de outra, e a interação de ambas contribui para que surja outra peça. Essa é a dinâmica, os mecanismos. As peças produção e financiador, que não haviam sido anteriormente citadas, passam a fazer parte dos mecanismos por conta das informações reveladas na seção que aborda a ação da organização Diamante.

Pelas características e pelos participantes da organização Diamante, comprova-se que ela é uma organização totalizante e complexa, ou seja, todas as peças estão presentes e, por conseqüência, seus mecanismos são de difícil compreensão. Verifica-se que existe relação da organização com diversos grupos estabelecidos em outros países, como Colômbia e Suriname. A movimentação financeira do grupo criminoso envolvia grandes somas de capital. Não existe comprovação de que os líderes do grupo, especificamente Leonardo Mendonça, aplicavam seus lucros em paraísos fiscais. Contudo, caso seja verdade a proposta do escritório de advocacia americano, é plausível a suspeita de que 
Figura 1

Dinâmica do Tráfico de Drogas e os Participantes da Organização Diamante

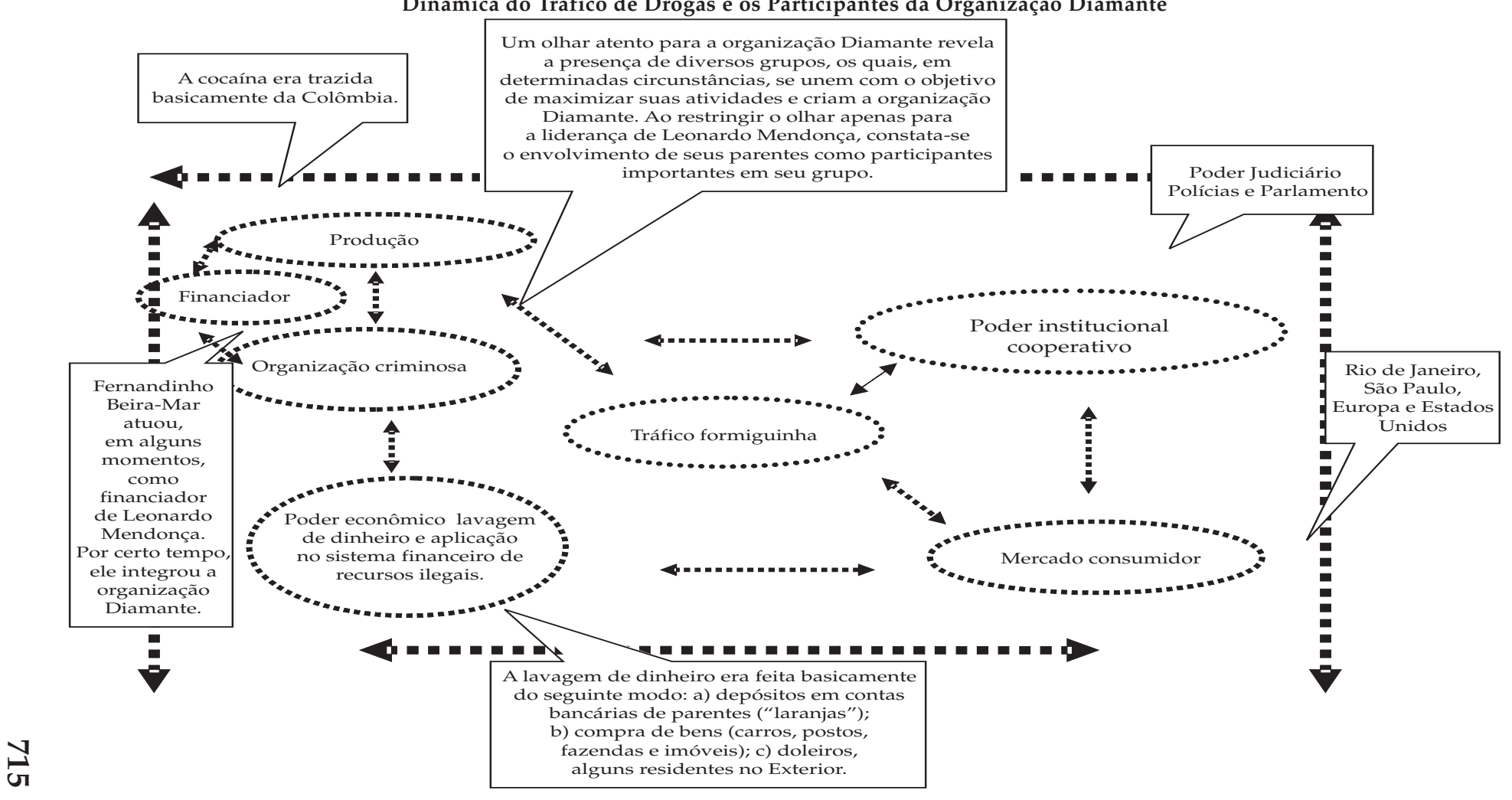


Leonardo poderia ter recursos aplicados em territórios onde o capital não sofre tributação.

A organização Diamante procurou atos de cooperação com diversos agentes institucionais que faziam parte da Polícia Federal, de tribunais superiores além de outras instituições, como a Justiça estadual. A organização exercia considerável influência sobre agentes do Estado.

A interação da organização de Leonardo Mendonça com outras organizações se explica pela lógica da ação coletiva (Olson, 1999): os grupos ou indivíduos recebem incentivos para atuar conjuntamente em busca de um mesmo objetivo, isto é, lucro por meio do tráfico de drogas. Nesse caso, Leonardo Mendonça teve um incentivo para atuar com o grupo de Fernandinho Beira-Mar, empréstimo financeiro. Já Beira-Mar pode ter sido incentivado pelo mercado consumidor a que Leonardo atendia, São Paulo e Europa. Com a interação dos grupos, um grupo totalizante - a união de várias organizações em uma só - surgiu e passou a agir.

Atos de cooperação - no caso, troca de benefícios - com os agentes estatais foram necessários, porque todos eles tinham interesse em maximizar seus benefícios. Diante disso, os agentes estatais foram usados como facilitadores de uma atividade criminosa e obtiveram ganhos. Regras informais entre sujeitos criminosos e agentes públicos foram criadas com o objetivo de facilitar o processo de negociação e coordenação. Nesse sentido, constata-se que o Estado é uma peça importante nos mecanismos do tráfico de drogas. Por intermédio dele, os atores ilícitos buscam a proteção institucional. Esta possibilita que as atividades dos grupos criminais organizados tenham condições de maximizar os benefícios advindos de suas atividades ilícitas.

Por conta da presença do poder institucional cooperativo, a peça poder econômico surge. Este, por sua vez, realimenta o processo de cooperação entre agentes estatais e grupos criminosos. É claro que a peça poder econômico pode surgir antes da peça poder institucional cooperativo, porém, isso não importa. O importante é a compreensão dos mecanismos e a visualização das peças que o integram.

As peças grupos criminosos, tráfico formiguinha e mercado consumidor estão em processo de interação. Desse modo, pode-se afirmar que o mercado consumidor é uma peça fundamental na compreensão dos mecanismos do tráfico de drogas, porque, sem ele, não existe demanda 
por drogas e, conseqüentemente, oferta. Não existindo demanda, as peças que ofertam drogas - grupos criminosos e tráfico formiguinha não têm razão de existir.

Os dados que revelam as ações da organização Diamante mostram que indivíduos se organizam com a intenção de buscar benefícios e maximizá-los. Leonardo Mendonça decidiu procurar outros indivíduos que faziam parte de outras organizações com o objetivo de conquistar mais benefícios. Se esse objetivo não existisse, uma grande organização não teria sido formada.

Portanto, o conceito mínimo/objetivo de crime organizado deve levar em consideração a intenção racional dos atores baseado na seguinte lógica: um indivíduo associa-se a outro com a intenção de aumentar seus ganhos. É claro que as características apontadas por Mingardi (1996) e as da United Nations (2002) não devem ser desprezadas. Inclusive, os dados empíricos aqui mostrados comprovam parte dessas características.

O tráfico de drogas ameaça a existência legal do poder estatal no Brasil. A atuação da organização Diamante revela que as instituições do Estado são usadas para facilitar atividades criminosas e proteger atores ilícitos. Diante disso, é necessário refletir sobre a eficiência das instituições, uma vez que elas são passíveis de influência de grupos criminosos. Quando essa influência se torna efetiva, as funções constitucionais do Estado são descaracterizadas e, por conseqüência, sua razão de existir. Nesse caso, a sociedade poderá passar a reconhecer o poder estatal como um estorvo, e não mais como um conjunto de instituições que provê o bem comum (Zaverucha e Oliveira, 2006).

(Recebido para publicação em maio de 2007) (Versão definitiva em outubro de 2007) 


\section{REFERÊNCIAS BIBLIOGRÁFICAS}

BOUDON, Raymond (org.). (1995), Tratado de Sociologia. Rio de Janeiro, Jorge Zahar (tradução de Teresa Curvelo).

ELSTER, Jon. (1986), Rational Choice. New York, New York University Press.

. (1994), Peças e Engrenagens das Ciências Sociais. Rio de Janeiro, Relume Dumará (tradução de Antônio Trânsito).

FURTADO, Bernardino. (2003), “MP Acusa Juiz de Coação em Goiás”. Correio Braziliense, 14 de junho.

MACHADO, Lia Osório. (2002), “Drug Trafficking and Money Laundering in the Amazon Region: Geoeconomic and Geopolitical Effects", in C. Geffray, G. Fabre e M. Schiray (orgs.), Globalisation, Drugs and Criminalisation: Final Research Report on Brazil, China, India and Mexico. França, Unesco/Most.

MINGARDI, Guaracy. (1996), O Estado e o Crime Organizado. Tese de doutorado, Faculdade de Filosofia e Ciências Humanas, USP, São Paulo.

. (1998), “O Que É Crime Organizado: Uma Definição das Ciências Sociais”. Revista do Ilanud, no 8, pp. 25-27.

O ESTADO DE S. PAULO. (2002), “STJ Abre Inquérito para Apurar Ligações com Tráfico: Investigação da PF Indica Existência de Esquema de Venda de Habeas-Corpus", 16 de dezembro. Disponível também em http://www.trfl.gov.br/usuario/segep/ascom/clipping/clipping_2002-12-16.htm\#stj, acessado em 14 de janeiro de 2003.

OLIVEIRA, Adriano. (2006), As Peças e os Mecanismos do Fenômeno Tráfico de Drogas e do Crime Organizado. Tese de doutorado em Ciência Política, Departamento de Ciência Política, UFPE, Recife.

OLSON, Mancur. (1999), A Lógica da Ação Coletiva: Os Benefícios Públicos e uma Teoria dos Grupos Sociais. São Paulo, Edusp (tradução de Fábio Fernandez).

PROCÓPIO, Argemiro. (1999), O Brasil no Mundo das Drogas. Petrópolis, Vozes.

PUTNAM, Robert D. (2002), Comunidade e Democracia: A Experiência da Itália Moderna (3a ed.). Rio de Janeiro, Editora FGV.

RATTON JÚNIOR, José de Amorim. (2003), Ulisses Liberto ou Prometeu Acorrentado?: Virtudes e Limites da Explicação da Ação na Obra de Jon Elster. Tese de doutorado em Sociologia, Departamento de Sociologia, UFPE, Recife.

RODRIGUES, Thiago M. S. (2002), "A Infindável Guerra Americana: Brasil, EUA e o Narcotráfico no Continente". São Paulo em Perspectiva, vol. 16, no 2, pp. 102-111.

(2003), Narcotráfico: Uma Guerra na Guerra. São Paulo, Desatino.

SARTORI, Giovanni. (1997), A Política (2a ed.). Brasília, Editora Universidade de Brasília (tradução de Sérgio Bath).

TERRA. (2003), "Casal de juízes é condenado por venda de sentenças". Disponível em: <http:/ / noticias.terra.com.br/brasil/interna/0,,OI209267-EI306,00.html>, acessado em 20 de novembro. 
TSEBELIS, George. (1998), Jogos Ocultos: Escolha Racional no Campo da Política Comparada. São Paulo, Edusp (tradução de Luiz Paulo Rouanet).

UNITED NATIONS OFFICE ON DRUGS AND CRIME - UNODC. (2002), Results of a Pilot Survey of Forty Selected Organized Criminal Groups in Sixteen Countries. Viena, CICP.

ZAFFARONI, Eugenio Raúl. (1996), “Crime Organizado: Uma Categorização Frustrada", in N. Batista (org.), Discursos Sediciosos: Crime, Direito e Sociedade, ano 1, vol. 1, pp. $45-68$.

ZALUAR, Alba. (1994), Condomínio do Diabo. Rio de Janeiro, Editora UFRJ.

. (2002), "Violence Related to Illegal Drugs, Easy Money and Justice in Brazil, 1980-1995", in C. Geffray, G. Fabre e M. Schiray (orgs.), Globalization, Drugs and Criminalisation: Final Research Report on Brazil, China, India and Mexico. França, Unesco/Most.

. (2004), Integração Perversa: Pobreza e Tráfico de Drogas. Rio de Janeiro, Editora FGV.

ZAVERUCHA, Jorge e OLIVEIRA, Adriano. (2006), “Reflexões sobre o Crime Organizado". Folha de S. Paulo, 16 de agosto. 


\section{Adriano Oliveira}

\section{ABSTRACT}

The Components and Mechanisms of Organized Crime and the Drug Traffic

This article uses the mechanism-based explanation as the method to analyze organized crime and the drug traffic. The authors begin by identifying the underlying components of such organized crime mechanisms and then proceed to describe a criminal organization dealing in drugs. The analysis draws on interviews, reports by Brazilian public prosecutors' offices, and police information. The empirical data confirm the components of organized crime and demonstrate the bankruptcy of public institutions, to the extent that criminal groups have succeeded in infiltrating these organizations from within and turning them into allies.

Key words: organized crime; state; mechanism-based explanation; drug traffic

\section{RÉSUMÉ}

Les Composantes et les Mécanismes du Crime Organisé dans l'Activité du Trafic de Drogue

L'explication par le moyen de mécanismes est la méthode utilisée dans cet article pour analyser le crime organisé et le trafic de drogue. Tout d'abord, on présente les pièces qu'on suppose constituer les mécanismes du crime organisé dans le trafic de drogue. Ensuite, on examine une organisation criminelle qui pratique ce trafic, ainsi que des entretiens, des dénonciations du Ministère Public et des informations policières. Les données empiriques servent à confirmer les pièces qui composent les mécanismes du crime organisé et montrent la faillite des institutions de l'État, puisque des groupes criminels attirent des acteurs de l'État et en font leurs collaborateurs.

Mots-clé: crime organisé; État; explication par des mécanismes; trafic de drogue 